\title{
Mini-Review
}

\section{Sutureless Scleral Fixated Posterior Chamber Intraocular Implantation}

\author{
Jiannan Liu ${ }^{1}$ and Shaomin Peng ${ }^{2 *}$ \\ ${ }^{1}$ Central South University, Aier School of Ophthalmology, Changsha, 410000, China \\ ${ }^{2}$ Harbin Aier Eye Hospital, Ocular Fundus Disease Ward, Harbin, 150001, China \\ *Corresponding author: Shaomin Peng, Central South University, Aier School of Ophthalmology, Chang- \\ sha, Harbin Aier Eye Hospital, Ocular Fundus Disease Ward, Harbin, China; E-mail: eyepsm@163.com
}

Received: 24 January, 2018; Accepted: 12 April, 2018; Published: 27 July, 2018

\begin{abstract}
Transscleral suture fixation plays a vital role during eye surgery, however postoperative complications still exist such as endophthalmitis, decentration or tilt of IOL (Intraocular Lens). Nowadays various sutureless intrascleral fixations of a Posterior Chamber IOL (PC-IOL) become popular in patients suffering insufficient capsular support. We enumerated and described 4 typical sutureless techniques of IOL fixation for aphakia. Further we also analyzed the advantages and disadvantages of the 4 techniques.
\end{abstract}

\section{Keywords}

Aphakia; IOL Implantation; Sutureless

\section{Review}

Nowadays sutureless intrascleral fixation of a Posterior Chamber Intraocular Lens (PC-IOL) becomes popular in patients suffering insufficient capsular support, as postoperative complications of transscleral suture fixation are difficult to avoid, such as suture exposure, suture degradation, suture-induced inflammation and suture hypotony [1-4]. Long-term studies showed that suture exposure rate remains $5 \%$ to $50 \%[1,3,5,6]$. Although new material suture method improved the problem of suture degradation and a number of surgeons advanced the suture method to decrease suture exposure rate $[7,8]$, the other postoperative complications still persist $[9,10]$. Anterior chamber IOL (AC-IOL) implantation is also a choice for surgeons, but postoperative complications of endothelial cell loss, pseudophakic bullous keratopathy, glaucoma and chronic iritis are intractable [11-13].

Maggi and Maggi [14] first described sutureless scleral fixation of IOLs in 1997, however it is a little bit complicated to perform. Then several ophthalmologists figured out various techniques to simplify the procedure of sutureless intrascleral fixation of IOLs, in which advantages and drawbacks coexisted.

Scharioth et al. [15] reported a technique of sutureless intrascleral fixation of a 3-piece IOL in 2007. A sclerocorneal incision for IOL implantation was prepared. Two straight sclerotomies 1.5 to $2.0 \mathrm{~mm}$ from the limbus and two scleral tunnels about $50 \%$ scleral thickness, starting directly from sclerotomies were performed by a 24-gauge cannula. After the IOL inserted and the trailing haptic left outside temporarily, the haptics were grasped and pulled out through the sclerotomies by a 25 -gauge forceps. Then the 25-gauge forceps were draw in the tunnel and pulled the haptic into the tunnel. No complications were detected during a 3-month follow-up of 5 cases [15]. Further studies showed postoperative complications happened within the first 4 weeks after surgery of 63 patients16, such as smooth vitreous hemorrhage $(3.17 \%)$, iris capture of IOL (1.59\%), recurrent dislocation of the IOLs (3.17\%) and persistent IOP elevation (1.59\%). In Scharioth's technique the sclerotomies and entrances of scleral tunnels for haptics were together, which makes the procedure of haptics pulled into the tunnels difficult and complex to operate. But this technique avoided the postoperative complications of transscleral suture fixation and enlightened other colleagues to develop more techniques of PC-IOL fixation for eyes without sufficient capsular support.

Agarwal et al. [17] introduced a sutureless intrascleral technique with scleral flaps and fibrin glue in 2008. Two partial-thickness limbal-based $2.5 \mathrm{~mm} \times 3.0 \mathrm{~mm}$ scleral flaps are conducted. Two straight sclerotomies are prepared with a 22-gauge needle about $1.5 \mathrm{~mm}$ from the limbus under the scleral flaps. One was placed at the upper edge of flap and the other at lower edge of the flap. A scleral tunnel incision is then created for implanting a 3-piece IOL. While one hand was implanting the IOL, the other grasped and pulled out the leading haptic through the sclerotomy with a 25-gauge forceps. After both haptics pulled out and externalized 
under the scleral flaps, fibrin glue was applied to seal the haptics and flaps together, so was the conjunctiva. In this study, it is safer to pull out the leading haptic during the IOL being implanted than Scharioth's method, as Agarwal's method decreased the rate of IOL falling into vitreous cavity. Also, Agarwal's method simplified the operation by omitting performing scleral tunnels for haptics fixation and pulling the haptics into the tunnels. And the flaps were glued hermetically to avoid egress of fluid, thereby decreasing the postoperative complications of endophthalmitis $[17,18]$. Few postoperative complications were found of 10 eyes [17]. However, a possibility of transmission of viral infections theoretically existed [19] and a large lamellar scleral flap was required. Further study of 210 glued IOL eyes conducted by Kumar et al. $[20,21]$ revealed postoperative complications including decentration (1.97\%), chronic macular edema (1.97\%), optic capture $(2.63 \%)$ and hyphema $(1.31 \%) 20$. There is no endophthalmitis (0\%) [20].

Yamane et al. [4] developed the technique of sutureless intrascleral PC-IOL fixation to be more operable and convenient in 2014. A sclerocorneal incision and 2 lamellar $1.5 \mathrm{~mm}$ scleral dissections about 50\% scleral thickness were performed $1.7 \mathrm{~mm}$ from the limbus. A 3-piece IOL was introduced into the anterior chamber and the trailing haptic was kept outside. A sclerotomy was conducted at the end of one lamellar scleral dissection with a 27-gauge needle. The leading haptic was guided into the lumen of the needle by a forceps and it was same to the trailing haptic. Both the haptics was pulled out through the sclerotomy by two needles. Two tunnels $2.0 \mathrm{~mm}$ were prepared with a 27 -gauge needle at the terminal of the scleral dissection opposite the sclerotomies. At last haptics were inserted into the tunnels. The postoperative complications of 35 eyes included iris capture of the IOL $(8.6 \%)$, transient ocular hypertension $(5.7 \%)$, and cystoid macular edema (2.9\%) [4]. It will be difficult to operate, when externalized the leading haptic before threading the trailing haptic into the lumen of the needle [22]. When sclerotomies and scleral tunnels are separated, there is more room for haptics pulled into the tunnels. But it is vulnerable for haptics when passed into the lumen of the needle [23], as you have to adjust the angle of the needle for haptics. There is another problem that it is not possible enough to keep the stability of the IOL, when inserting only 1.5 $\mathrm{mm}$ of the haptics into the scleral tunnel [24].

Ohta et al. [25] described a Y-fixation technique in 2014. Two Y-shaped incisions were performed $2.0 \mathrm{~mm}$ from the limbus and two sclerotomies prepared at the Y-shaped incision with a 24-gauge microvitreoretinal knife. Two scleral tunnels were conducted at the branching point of the Y-shaped incision. The procedure of IOL implantation and haptics pulled out was very similar to Agarwal's method. Then the haptics were inserted into the tunnels. At last a suture was placed in the scleral bed to prevent the IOL shifting immediately after surgery, and the sclera is sutured. The postoperative complications of 44 eyes contained vitreous hemorrhage (6\%), retinal detachment (2\%), IOL dislocation and tilt (5\%), and temporary IOP increase (2\%) [25]. Ohta considered his technique to be stronger IOL fixation than others', while others' techniques didn't show severe IOL dislocation and tilt $[4,15,26,27]$. More injury accompanied the Y-shaped incisions and suture perplexed the operation.

Takayama et al. [28] advanced the sutureless intrascleral technique without applying a wide conjunctival incision in 2015. A $3.0 \mathrm{~mm}$ sclerocorneal incision was prepared and a transconjunctival scleral incision was performed $1.5 \mathrm{~mm}$ from the limbus with a $22-\mathrm{G}$ needle. The leading haptic was guided by a $24-\mathrm{G}$ catheter needle. Then the same procedure was for the trailing haptic. A scleral tunnel conducted by a $30-\mathrm{G}$ needle at the scleral incision and the tip of the needle was exposed from the sclera and conjunctiva. Then another $30-\mathrm{G}$ needle was introduced into the tunnel at the tip of the first 30-G needle. The haptic was inserted into the lumen of the second needle and was guided into the tunnel. This procedure is performed for both the leading and trailing haptics. Complications of 12 eyes included vitreous haemorrhage $(16.7 \%)$, and postoperative hypotony ( $8.3 \%)$, and iris capture $(8.3 \%)$ [28]. Patients undergoing this technique would be more comfortable and conjunctival space would fulfilled fine conditions for glaucoma surgery in the future, although it is complicated to perform the method.

Various sutureless intrascleral PC-IOL fixations have been reported. In the techniques described above, diverse means of preparing sclerostomies, ways of pulling out haptics and methods of introducing the haptics into tunnels were figured out, and scleral flaps and tunnels were conducted in order to immobilize the haptics. Good stability and few postoperative complications are in common. More practical techniques would be developed to be more operable and less injured to patients with the passage of time. And longer term and follow-up studies are considered.

\section{References}

1. Epstein E (1989) Suture problems. J Cataract Refract Surg 15: 116.

2. Arkin MS, Steinert RF (1994) Sutured posterior chamber intraocular lenses. Int Ophthalmol Clin 34: 67-85.

3. Majunke N, Baranowski A, Zimmermanni W, Heinisch C, Wilson $\mathrm{N}$, et al. (2009) A suture not always the ideal solution: problems encountered in developing a suture-based PFO closure technique. Catheter Cardiovasc Interv 73: 376-382.

4. Yamane S, Inoue M, Arakawa A, Kadonosono K (2014) Sutureless 27-gauge needle-guided intrascleral intraocular lens implantation with lamellar scleral dissection. Ophthalmology 121: 61-66.

5. Heidemann DG, Dunn SP (1992) Transsclerally sutured intraocular lenses in penetrating keratoplasty. Am J Ophthalmol 113: 619-625.

6. Lubniewski AJ, Holland EJ, Van Meter WS, Gussler D, Parelman J, et al. (1990) Histologic study of eyes with transsclerally sutured posterior chamber intraocular lenses. Am J Ophthalmol 110: 237-243.

7. Hannush SB (2000) Sutured posterior chamber intraocular lenses: indications and procedure. Curr Opin Ophthalmol 11: 233-240.

8. Yalniz-Akkaya Z, Burcu A, Uney GO, Abay I, Eksioglu U, et al. (2014) Primary and secondary implantation of scleral-fixated posterior chamber intraocular lenses in adult patients. Middle East Afr J 


\section{Ophthalmol 21: 44-49.}

9. Khan MA, Gupta OP, Smith RG, Ayres BD, Raber IM, et al. (2016) Scleral fixation of intraocular lenses using Gore-Tex suture: clinical outcomes and safety profile. Br J Ophthalmol 100: 638-643.

10. Khan MA, Rahimy E, Gupta OP, Hsu J (2016) Combined 27-Gauge Pars Plana Vitrectomy and Scleral Fixation of an Akreos AO60 Intraocular Lens Using Gore-Tex Suture. Retina 36: 1602-1604.

11. Numa A, Nakamura J, Takashima M, Kani K (1993) Long-term corneal endothelial changes after intraocular lens implantation. Anterior vs posterior chamber lenses. Jpn J Ophthalmol 37: 78-87.

12. Smith PW, Wong SK, Stark WJ, Gottsch JD, Terry AC, et al. (1987) Complications of semiflexible, closed-loop anterior chamber intraocular lenses. Arch Ophthalmol 105: 52-57.

13. Apple DJ, Brems RN, Park RB, Norman DK, Hansen SO, et al. (1987) Anterior chamber lenses. Part I: Complications and pathology and a review of designs. J Cataract Refract Surg 13: 157-174.

14. Maggi R, Maggi C (1997) Sutureless scleral fixation of intraocular lenses. J Cataract Refract Surg 23: 1289-1294.

15. Gabor SG, Pavlidis MM (2007) Sutureless intrascleral posterior chamber intraocular lens fixation. J Cataract Refract Surg 33:18511854.

16. Scharioth GB, Prasad S, Georgalas I, Tataru C, Pavlidis M (2010) Intermediate results of sutureless intrascleral posterior chamber intraocular lens fixation. J Cataract Refract Surg 36: 254-259.

17. Agarwal A, Kumar DA, Jacob S, Baid C, Agarwal A, et al. (2008) Fibrin glue-assisted sutureless posterior chamber intraocular lens implantation in eyes with deficient posterior capsules. J Cataract Refract Surg 34: 1433-1438.

18. Jacob S (2017) Intrascleral IOL Fixation. Asia Pac J Ophthalmol (Phila) 6:381-387.
19. Schlegel A, Immelmann A, Kempf C (2001) Virus inactivation of plasma-derived proteins by pasteurization in the presence of guanidine hydrochloride. Transfusion 41: 382-389.

20. 20. Kumar DA, Agarwal A, Agarwal A, Prakash G, Jacob S (2011) Glued intraocular lens implantation for eyes with defective capsules: A retrospective analysis of anatomical and functional outcome. Saudi J Ophthalmol 25: 245-254.

21. Kumar DA, Agarwal A (2013). Glued intraocular lens: a perspective. Expert Rev Ophthalmol 8: 355-361.

22. Rodriguez-Agirretxe I, Acera-Osa A, Ubeda-Erviti M (2009) Needle-guided intrascleral fixation of posterior chamber intraocular lens for aphakia correction. J Cataract Refract Surg 35: 2051-2053.

23. Saleh M, Heitz A, Bourcier T, Speeg C, Delbosc B et al. (2013) Sutureless intrascleral intraocular lens implantation after ocular trauma. J Cataract Refract Surg 39: 81-86.

24. Karadag R, Celik HU, Bayramlar H, Rapuano CJ (2016) Sutureless Intrascleral Fixated Intraocular Lens Implantation. J Refract Surg 32: 586-597.

25. Ohta T, Toshida H, Murakami A (2014) Simplified and safe method of sutureless intrascleral posterior chamber intraocular lens fixation: Y-fixation technique. J Cataract Refract Surg 40: 2-7.

26. Todorich B, Thanos A, Woodward MA, Wolfe JD (2016) Sutureless Intrascleral Fixation of Secondary Intraocular Lens Using 27-Gauge Vitrectomy System. Ophthalmic Surg Lasers Imaging Retina 47: 376-379.

27. Karadag R, Bayramlar H, Cakici O (2015) Sutureless scleral fixation of intraocular lenses. Graefes Arch Clin Exp Ophthalmol 253: 1817-1818.

28. Takayama K, Akimoto M, Taguchi H, Nakagawa S, Hiroi K (2015) Transconjunctival sutureless intrascleral intraocular lens fixation using intrascleral tunnels guided with catheter and 30-gauge needles. Br J Ophthalmol 99: 1457-1459. 